\title{
Back to Basics
}

\section{Proton Pump Inhibitors and Pain}

Howard S. Smith, MD, Reena Dhingra, Lori Ryckewaert, FNP, and Dave Bonner, PhD

From: Albany Medical College, Department of Anesthesiology, Albany, NY

Dr. Smith is Associate Professor \& Academic Director of Pain Management, Albany Medical College, Department of

Anesthesiology, Albany, NY. Dhingra is a fourth year medical student, and Research Assistant,

Albany Medical College, Albany,

NY; Ryckewaert is a Research Assistant, Albany Medical College, Albany, NY; Dr. Bonner is President and CEO, Adirondack Area Network, Castleton, NY

Address correspondence: Howard S. Smith, MD Associate Professor \& Academic Director of Pain Management Albany Medical College Department of Anesthesiology 47 New Scotland Avenue; MC-131 Albany, New York 12208

E-mail: smithh@mail.amc.edu

Disclaimer: There was no external funding in the preparation of this manuscript.

Conflict of interest: None.

Manuscript received: 0 Revised manuscript received: Accepted for publication:
There may be a relationship between proton pump inhibitors (PPIs) and iron absorption. PPIs may decrease the amount of iron absorbed gastrointestinally specifically due to alteration of the $\mathrm{pH}$ in the duodenum. Restless legs syndrome (RLS) is a sensorimotor disorder that includes an urge to move legs, accompanied or caused by uncomfortable and unpleasant sensations in the legs; the urge to move begins or worsens during periods of rest or inactivity, the urge to move is partially or totally relieved by movement, and the urge is worse or only occurs at night. In the majority of the restless leg syndrome population, the sensation is deep seated, often described as being in the shin bones, and most commonly felt between the knee and ankle. It may be described as a creepy, shock-like, tense, electric, buzzing, itchy, or even numb sensation. A subpopulation of this restless leg syndrome patient population experiences restless leg syndrome associated pain (RLSAP) that has been described as a deep "achy pain." This pain has not been found to be relieved by many of the typical over the counter analgesics. Often, constant movement of the legs appears to be the only remedy, as these sensations usually appear during periods of rest.

Furthermore, there appears to be an association between iron deficiency and those suffering from Restless Leg Syndrome (RLS). The authors theorize that there may be a possible correlation between PPIs and the symptoms (e.g. pain) associated with RLS. The authors propose that PPIs, such as omeprazole, may interfere with iron absorption in certain patients and that a subpopulation of patients who develop significant iron deficiency characterized by low serum ferritin levels while on PPIs may also develop RLS-like symptoms (including RLSAP). While there is no robust direct evidence to support any associations of PPIs and iron deficiency or PPIs associated with RLS-like symptoms (including RLSAP), it is hoped that this manuscript may spark research efforts on this issue.

Key words: Proton pump inhibitor (PPI), Restless Leg Syndrome (RLS), iron deficiency, pain, iron absorption, Restless Leg Syndrome Associated Pain (RLSAP)

Pain Physician 2009; 12:1013-1023
D) estless legs syndrome (RLS) is a fairly common neurological disorder where one suffers from symptoms of spontaneous and continuous leg movements that can be associated with unpleasant paresthesias. Many sufferers describe this condition as tingling, crawling, and pulling in the lower part of the legs (1). In fact, many of these sensations can also occur in the thighs, feet, and upper body. In the majority of the RLS population, the sensation is deep seated, often described as being in the shin bones, and most commonly felt between the knee and ankle. It may be described as a creepy, shock-like, tense, electric, buzzing, itchy, or even numb sensation. A portion of this patient population may experience a deep "achy pain" referred to as RLS associated pain (RLSAP). This pain is generally refractory to simple conservative therapy and over the counter analgesics. Constant movement of the legs appears to be the only 
reliable nonpharmacologic maneuver which results in resolution of these sensations (1). RLS and RLSAP appear to be related to iron deficiency. The authors propose that proton pump inhibitors (PPIs), such as omeprazole, may interfere with iron absorption in certain patients and that a subpopulation of patients who develop significant iron deficiency with low serum ferritins while on PPIs may also develop RLSlike symptoms or exacerbation of pre-existing RLS symptoms.

\section{Restless Leg Symidome}

Restless legs syndrome is a sensorimotor disorder that often has a profound impact on sleep (2). The severity of the symptoms varies widely, ranging from occurring only occasionally in a stressful situation to nightly and severe, with almost total disruption of sleep. An RLS severity rating scale has been developed by the International RLS Study Group (IRLSSG) to evaluate this wide range of symptom severity (3).

All 4 National Institute of Health (NIH) criteria are essential to the diagnosis of RLS. The 4 diagnostic criteria are:

- Criterion 1 - An urge to move the legs, usually accompanied or caused by uncomfortable and unpleasant sensations in the legs. (Sometimes the urge to move is present without the uncomfortable sensations and sometimes the arms or other body parts are involved in addition to the legs.)

- Criterion 2 - The urge to move or unpleasant sensations begin or worsen during periods of rest or inactivity such as lying or sitting.

- Criterion 3 - The urge to move or unpleasant sensations are partially or totally relieved by movement, such as walking or stretching, at least as long as the activity continues.

- Criterion 4-The urge to move or unpleasant sensations are worse in the evening or night than during the day or only occur in the evening or night. (When symptoms are very severe, the worsening at night may not be noticeable but must have been previously present) (4).

The clinical diagnostic criteria for RLS reviewed in 2003 by the International Restless Legs Study Group included an urge to move legs accompanied or caused by uncomfortable and unpleasant sensations in the legs, the urge to move begins or worsens during periods of rest or inactivity, the urge to move is partially or totally relieved by movement and the urge is worse or only occurs in the night.
The RLS Center at Johns Hopkins developed and validated the Hopkins telephone diagnostic interview (HTDI) (5). Diagnosis was made primarily on the basis of questions which examined 6 features of RLS:

1. leg discomfort and;

2. an urge to move;

3. that are present at rest;

4. occur frequently when lying down as well as when sitting;

5. symptoms are relieved by movement; and

6. demonstrate a circadian pattern with peak symptoms occurring at night or in the evening (5). Definite RLS required that the subject affirm all 6 features except either 1 or 4 (6). Neither of these 2 features forms part of the necessary diagnostic criteria for RLS (4).

Symptoms of RLS have been seen in up to $15 \%$ of the population (7). Although the primary etiology of RLS is unknown, a positive family history has been found in over $40 \%$ of patients suffering from idiopathic RLS, suggesting a genetic basis for this syndrome (8). RLS may be primary (genetic or idiopathic), secondary (i.e., related to other medical or neurological disorders), or arise from a combination of factors (e.g., positive family history, iron deficiency, uremia). The most important associations of secondary RLS are with end-stage renal disease or iron deficiency (9). Nevertheless, the pain associated with RLS can be significant, as one of the main hallmarks of RLS is extreme discomfort in the legs, most often bilaterally. Some patients suffering from RLS have described this discomfort as frank pain.

RLS is an important condition because it is common, it causes significant distress to sufferers, it may be the presenting feature of serious underlying conditions, and it is treatable. The following drugs are considered efficacious for the treatment of RLS: levodopa, ropinirole, pramipexole, cabergoline, pergolide, and gabapentin (10). Drugs considered likely efficacious are rotigotine, bromocriptine, oxycodone, carbamazepine, valproic acid, and clonidine. Drugs that are considered investigational are dihydroergocriptine, lisuride, methadone, tramadol, clonazepam, zolpidem, amantadine, and topiramate. Magnesium, folic acid, and exercise are also considered to be investigational (10). Intravenous iron dextran is likely efficacious for the treatment of RLS secondary to end-stage renal disease and investigational in RLS subjects with normal renal function (10). The efficacy of oral iron is considered investigational; however, its efficacy appears to depend on the iron status of subjects (10). 


\section{RLS ANd PaIn}

Patients with RLS may show some features also seen in neuropathic pain. Peripheral neuropathy is present in up to $36 \%$ of late-onset RLS patients and RLS patients may have abnormalities in central sensory processing (11). Furthermore, the sensations experienced by RLS patients have been shown to be relieved by treating the patients with analgesic medications, such as opiates and gabapentin, to which neuropathic pain also responds (12).

Stiasny-Kolster et al (13) evaluated pain sensitivity in 11 patients (age $60 \pm 10$ years) with "primary" RLS (disease duration $18 \pm 15$ years) and 11 age- and gender-matched healthy control subject. Pin-prick pain ratings in RLS patients were significantly elevated by a factor of 5.3 in the upper limb and by a factor of 6.4 in the lower limb indicating a significant generalized static hyperalgesia more pronounced in the lower limb (13). Acute single-dose dopaminergic treatment with $100 \mathrm{mg}$ levodopa $+25 \mathrm{mg}$ benserazide, 90 minutes prior to the evening measurements largely resolved patients' RLS symptoms, but had no effect on pin-prick pain. Static hyperalgesia to pinprick, however, was significantly reversed (median reduction $-74 \%$ ) by long-term individually tailored dopaminergic treatment (13).

Secondary RLS is known to be associated with polyneuropathy (14), and in particular with small fiber sensory neuropathy (SFSN) (15-17), possibly representing a peculiar form of neuropathic pain (15). The relationship between pain and RLS has been investigated mainly in primary, non-neuropathic RLS patients (13). To investigate the relationship between pain and RLS, Gemignani et al (18) evaluated retrospectively a series of patients with polyneuropathy and neuropathic pain or dysesthesia as main symptoms, using a tentative mechanismbased classification of neuropathic pain $(19,20)$.

The clinical severity of RLS was graded on the Johns Hopkins RLS Severity Scale (JHRLSSS) (21), based on the reported time of usual symptom onset: 1 for mild, defined as usual symptom onset at bedtime; 2 for moderate, defined as after 6 pm but before bedtime; or 3 for severe, defined as before $6 \mathrm{pm}$.

Gemignani et al (18) evaluated the occurrence of RLS in 102 consecutive patients with polyneuropathy manifesting with neuropathic pain or dysesthesia. The patients were classified in subgroups characterized respectively by allodynia ("hyperphenomena") with reported unpleasant sensations evoked by tactile stimuli, and hypoalgesia ("hypophenomena") with absent pain sensation to pinprick. RLS was present in 41/102 patients $(40.2 \%)$. It was significantly more frequent in the hypoalgesia (23/37) than in the allodynia subgroup $(9 / 31 ; P=.008)$ and in the not classifiable cases (9/34; $P=.004)$.

\section{Iron Absorption}

The average adult stores about 1 to 3 grams of iron in his or her body. There is a precise balance between the dietary uptake and loss (22). However, due to the fact that there are not any physiologic mechanisms of iron excretion that exist, it is the absorption alone that regulates body iron stores (23). Absorbed iron is bound in the bloodstream by the glycoprotein named transferrin. Normally, about $20 \%$ to $45 \%$ of transferrin binding sites are occupied.

Iron absorption occurs predominantly in the duodenum and upper jejunum. However, it is the physical state of iron that enters the duodenum that greatly influences its absorption. The majority of non-heme iron is in the ferric form $\left(\mathrm{Fe}^{3+}\right)$ supplies at least 2/3 of dietary iron requirements and the availability of iron in this pool. This iron is critically dependent on the stomach and duodenum. The gastric hydrochloric acid is one of the most important factors that assist optimal absorption of iron (24). In vitro experiments investigating the capacity of gastric juice produced by pentagastrin challenge, to release radioiron through solubilization from biosynthetically labeled bread, showed that below $\mathrm{pH} 2.5$ there was a linear relation between $\mathrm{pH}$ and percentage solubility (25). In contrast, samples of gastric juice with $\mathrm{pH}$ values above 2.5 released negligible amounts of iron, whereas in linked in vivo studies a close correlation was demonstrated between iron absorption and the capacity of gastric juice to release food iron in both controls and patients. The finding that above $\mathrm{pH} 2.5$ there was a failure to solubilize and absorb non-heme iron (25) is highly relevant to the current study because PPIs are potent inhibitors of gastric acid. For example, the administration of $20 \mathrm{mg}$ omeprazole daily leads to an intragastric $\mathrm{pH}$ of $>4$ for at least 8 hours in $67 \%$ of individuals and a median intragastric $\mathrm{pH}$ over 24 hours of > 3.6 (26). At these levels of gastric acidity, negligible amounts of non-heme iron would be released from dietary components (25) and reduction of ferric iron and formation of ferric chelates would be impaired (27). This would have a major impact on iron absorption because ferrous iron and ferric chelates normally remain soluble in 
the alkaline environment of the bulb/post bulbar regions $(28,29)$ facilitating the transport of iron across the intestinal epithelium by mucosal iron transporters and accessory proteins (30).

Iron absorption consists of an uptake step in which iron is transported across the apical membrane of the enterocyte, and transfer, the movement of iron across the basolateral membrane into the portal circulation (30). Ferric iron in the duodenal lumen is reduced to the insoluble ferrous $\left(\mathrm{Fe}^{2+}\right)$ form via a duodenal cytochrome B. Ferrous iron $\left(\mathrm{Fe}^{++}\right)$is then taken up by transporters. The apical and basolateral transporters have been identified as divalent metal transporter 1 (DMT1) and ferroportin 1 (FP1) respectively and, furthermore, the duodenal expression of both carriers is increased in Hereditary Hemochromatosis (HH) (31-33). DMT1 and FP1 are centrally involved in iron uptake/transfer in the duodenum and in the adaptive changes of iron homeostasis to iron deficiency and overload (31). The increase in ferroportin expression is caused by a relative lack of the iron regulatory hormone hepcidin, a peptide that regulates cellular iron efflux by binding to ferroportin and inducing its internalization (34). Hepcidin is deficient in both treated and untreated $\mathrm{HH}$ $(35,36)$, resulting in uncontrolled activity of ferroportin and increased efflux of iron from the enterocyte. While low levels of intracellular iron in the enterocyte could result in increased expression of the apical transporter, by stabilizing mRNA transcripts through enhanced binding of iron-responsive protein to the $3^{\prime}$ iron-responsive element, this is not known with certainty (31). The uptake of the ferrous ion depends on a variety of factors, and one of the major contributors is the solubility of the ferric iron. The solubility and uptake of ferric iron is increased when exposed to a lower $\mathrm{pH}$ in the proximal duodenum (31). This lower $\mathrm{pH}$ environment is accomplished by hydrochloric acid. In fact, the absorption of other various nutrients such as vitaminutes B12 and calcium are also affected by the $\mathrm{pH}$ in the duodenum. Thus it can be seen that gastric acid may enhance the uptake of ferric iron due to the lowering of $\mathrm{pH}$ (37).

\section{PPIs and Iron Deficiency}

If the acidic environment in the stomach plays such a prominent role for iron absorption, perhaps a hypochlorohydric state can lead to iron deficiency. Thus if the production of gastric acid production is impaired by a PPI such as omeprazole, then the $\mathrm{pH}$ will not be low enough to enhance the ferric iron up- take, ultimately leading to a reduction in the amount of iron absorbed $(31,37)$. It is important to note that iron deficiency has been described in various studies in patients with a partial or total gastrectomy or with atrophic gastritis. Nevertheless, there have been no large controlled trials to actually give a definitive relationship between PPI therapy and iron absorption.

Long-term use of PPIs has not been reported to compromise iron status in normal subjects $(39,40)$, possibly because many individuals with intact regulatory mechanisms of iron absorption are able to adapt to impaired bioavailability of non-heme iron, however, these studies are small and do not provide robust evidence that long-term PPI therapy do not compromise iron status. One interpretation of the results of Hutchinson and colleagues (40) is that such adaptation does not occur in $\mathrm{HH}$. These patients demonstrate an expression profile of mucosal iron transporters (31) and iron absorption kinetics more in common with iron deplete than with iron replete individuals (41-43), and, as a result may not be able to further increase iron absorption. Nevertheless, the finding that patients with $\mathrm{HH}$ who were taking a PPI still required the removal of $0.5(0.2)$ liter of blood annually to maintain normal iron balance suggests that an additional source of iron was available in the habitual diet. Hutchinson et al have argued that this was likely to be heme iron because absorption of this form of iron is not dependent on gastric $\mathrm{HCl}(41,44)$ and furthermore, is increased in hemochromatosis (41). It is also possible that absorption of heme iron plays an important role in ensuring dietary iron availability in normal subjects on a long-term PPI. The authors postulate that there exists a subpopulation of patients (perhaps those without robust compensatory mechanisms) that may develop iron deficiency due to long-term high dose PPI therapy.

A subpopulation of patients may exist in which proton pump inhibitors (PPI) may contribute towards iron deficiency. This subpopulation of patients may require a low $\mathrm{pH}$ environment in order to optimally and effectively absorb iron. We refer to these patients as strongly $\mathrm{pH}$-dependent iron absorbers. Some of these patients may also develop low ferritin levels during long-term high dose therapy with $\mathrm{H} 2$ receptor antagonists. In particular, it has been shown that patients suffering from hereditary hemochromatosis $(\mathrm{HH})$ have been able to suppress their dietary non-heme iron with PPIs. Hereditary hemochromatosis, the most common inherited single gene defect disorder in those of the Northern European descent, is a condition where there 
is increased intestinal absorption of iron, with deposition of iron in multiple organs $(45,46)$. It was suggested by Hutchinson et al (40) that administration of a PPI to a patient suffering from $\mathrm{HH}$ can actually inhibit absorption of the dietary non-heme iron and ultimately limit the accumulation of iron in tissue stores. In their study (40), there was a significant reduction $(P>0.001)$ in the volume of blood removed annually before (2.5 (0.25) I) and while taking (0.5 [0.25] I) PPIs. Administration of a PPI for 7 days suppressed absorption of non-heme iron from the meal as shown by a significant reduction (all $P$ $<0.01$ ) in: area under the serum curve (2145 [374] versus 1059 [219], \% recovery of administered iron at peak serum iron (20.5 [3.2] versus 11.0 [2.0] \%) and peak serum iron (13.6 [2.4] vs. 6.1 [1.2] $\mu \mathrm{mol} / \mathrm{l}$ ) (all values are before vs. during PPI). The authors found that the administration of a PPI for 7 days suppressed absorption of nonheme iron from the test me al. This further supports the role of PPIs in decreasing iron absorption (40).

Hutchinson et al (40) demonstrated a significant PPI-related reduction in the absorption of non-heme iron in patients with $\mathrm{HH}$, and this, together with the observation that there was a significant reduction in phlebotomy requirements in patients taking PPIs over a long period, suggests that gastric acid suppression can inhibit the absorption of non-heme iron from the habitual diet in $\mathrm{HH}$.

In only one group of patients has it been found that long-term PPI use does not significantly cause iron deficiency and that it is patients suffering from Zollinger-Ellison Syndrome. These patients produce increased levels of gastrin leading to excess gastric hydrochloric acid, and may exhibit alterations in the absorption of iron. Thus, these patients often are put on continuous treatment with omeprazole or other various gastric antisecretory drugs. It has been shown that in this population, the long-term use of PPIs did not cause decreased body iron stores or iron deficiency. However we must keep in mind that these patients may have had altered absorption of iron to begin with prior to PPI treatment due to their condition (39). Furthermore, these patients do not represent the typical population and with so much excess gastric hydrochloric acid, it is not surprising that PPIs did not lead to decreased iron stores in this subpopulation. A definitive answer about the relationship between PPI therapy and iron absorption can be provided only through a large, multicenter, well-designed controlled trial with simultaneous studies of iron absorption.

\section{Iron Deficiency and Restless Legs SYNDROME}

When Ekbom (47) provided the first modern medical descriptions of RLS, he noted a high prevalence of iron deficiency among patients with RLS. This striking relation led a contemporary of Ekbom, another Swedish neurologist Nordlander $(48,49)$, to not only propose that iron deficiency in some body tissue caused RLS but also to successfully treat 21 of 22 patients with RLS with relatively large doses of intravenous (IV) iron. Since 2000, investigators have gained a greater understanding of the pathophysiology of RLS, particularly in relation to the importance of iron metabolism (50).

The improvement in RLS with dopaminergic agonists and the worsening of symptoms with dopaminergic antagonists suggest an important role for the dopamine neurotransmitter system in the central nervous system in the pathogenesis of RLS. Positron emission tomography and single photon emission computed tomography studies have found decreased activity of the dopamine D2-receptor in the striatum of RLS patients, consistent with a role for a subcortical dysfunction of the dopaminergic system in RLS (50). Iron is an essential cofactor for tyrosine hydoxylase, which is the rate-limiting enzyme for dopamine synthesis. In animal studies, iron deficiency is associated with hypofunction of dopamine D2 receptors that is corrected by iron replacement (51). The fact that many of the established secondary causes of RLS share disturbance of iron metabolism as a common feature, that the degree of iron deficiency correlates well with symptoms, and that iron is an effective therapy, at least in irondeficient patients, provide clinical support for the importance of iron deficiency in the pathogenesis of RLS (52). Thus, the current hypothesis is that RLS involves a functional disturbance of dopamine neurotransmission in subcortical areas of the brain, provoked by regional iron deficiency or by genetic factors or both, resulting in decreased inhibition of the sensorimotor cortical system and (particularly during sleep) of the spinal system (52).

There have been an increasing number of studies suggesting a causal association between iron deficiency and RLS. Early et al (53) showed that serum ferritin levels inversely correlated with RLS severity. High doses of IV iron reduce the RLS symptoms in patients with end stage renal disease (54). Similarly, the decreased blood volume that occurs with delivery provides a rapid improvement in access to iron stores and there is a corresponding rapid remission of any RLS symptoms 
(55). Increasing the body iron stores in patients with RLS and iron deficiency can provide complete relief from all RLS symptoms in some patients (56). These considerations led to our hypothesis: All conditions that compromise iron availability and/or promote iron deficiency may increase the risk of developing RLS-like symptoms. This hypothesis has been shown for multiple conditions with diminished iron stores/ availability, (e.g.; gastric surgery [57] and low-density lipoprotein apheresis $[58,59])$. It is interesting that the serology measures of iron status most frequently used have limitations. They neither provide a direct measure of cellular or bone marrow iron status nor an accurate measure of neuronal iron status. Despite these problems, one community based study found higher serum transferrin receptor indicating iron compromise for RLS compared to control subjects (60) but this was not found in another similar study (61). Serum ferritin provides the generally accepted best single measure of iron stores $(62,63)$. The phase-reactive property of ferritin, however, sometimes produces falsely elevated values even in the face of iron deficiency (e.g., ferritin is an acute phase reactant and will be increased with significant inflammation). Given the ferritin measurement problems, it has been recommended that patients with RLS with ferritin of $50 \mathrm{mcg} / \mathrm{L}$ or less be considered for iron treatment (64). An un-blinded study (65) as well as a double-blind controlled study (67) found that oral iron treatment in patients with RLS and iron deficiency reduces RLS symptoms particularly for those with lower ferritin values. Serum ferritin somewhat indirectly reflects body iron stores and in 2 studies correlated with RLS severity $(65,66)$. Moreover, patients with RLS who develop iron deficiency show marked exacerbation of their symptoms. Thus, any sudden worsening of RLS symptoms unrelated to medication changes has to be considered as likely indicating blood loss or another cause of iron deficiency.

Two MRI studies using the GESFIDE (gradientecho sampling of free induction decay and echo) sequence (a reasonably efficient means of assessing various transverse relaxation rates via sampling a train of echoes which correlates with iron content) have found significantly reduced iron content in the substantia nigra more marked for those patients with RLS whose symptoms started before they were 45 years old ("early-onset RLS") $(68,69)$. In both of these studies the MRI measurement of nigral iron concentration correlated inversely with clinical ratings of disease severity $(68,69)$. An independent study using B-mode transcranial ultrasound imaging showed marked hypoechogenicity for the nigra area in patients with RLS compared to controls consistent with reduced nigral iron (70). Thus, we have independent studies using different methods indicating nigral iron compromise in patients with RLS.

Autopsy studies from 7 patients with RLS (ages $53,65,76,77,83,84,85)$ compared to 5 control individuals with no neurologic history (ages 48, 66, 67, 74, 84) provide strong confirmation of the brain iron deficiency in RLS and also give an interesting picture of the nature of this deficiency. Examination of stained sections from the substantia nigra of patients with RLS and matched controls showed decreased iron and ferritin along with increased transferrin suggesting a potential defect in the regulation of transferrin receptors (71).

RLS may result from a defect in iron regulatory protein 1 in neuromelanin cells that promotes destabilization of the transferrin receptor mRNA, leading to cellular iron deficiency (72). Examination of the homogenates of only the isolated neuromelanin cells showed that RLS compared to controls exhibited decreased levels of ferritin, divalent metal transporter 1 , ferroportin, and transferrin receptor as well as increased iron regulatory protein 2 (IRP2) consistent with cellular iron deficiency but also an unexpected decreased IRP1 both in its active and aconitase form (72). The marked decrease in IRP1 may explain at least in part the decreased transferrin receptor expression, possibly limiting cellular iron access and contributing to the brain iron deficiency or even to reduced transport across the blood brain barrier. The decreased IRP1 may be secondary to the lack of availability of iron or reflect a primary pathology of RLS (72).

Nordlander $(48,49)$ suspected that iron deficiency may contribute to RLS since iron deficiency anemia was identified in $25 \%$ of the RLS patients that Karl Ekbom (49) originally described in 1945; and conducted the first published trial of IV iron treatment of RLS. Nordlander reported that IV iron therapy produced complete and fairly lasting relief from RLS symptoms for all but one of 22 subjects treated. Earley et al (73) recently did a careful evaluation of response to a single dose of 1,000 $\mathrm{mg}$ of IV iron dextran using both clinical ratings and objective measures of leg movements during the sleep period. They reported that 6 of 10 patients with RLS had almost, if not, complete relief from all RLS symptoms for at least 2 weeks and for most patients the relief lasted longer than 2 months. 
This relief was documented both on subjective scales and also on the objective measure of leg movements.

MRI studies and a transcranial ultrasound study showed reduced amount of nigral iron in those with RLS, compared to the controls (53). Thus there has been evidence gained using both peripheral and central measures that supports a correlation between iron deficiency and RLS. Earley et al (52) have proposed that iron deficiency leads to increased dopamine production and more extracellular dopamine levels. The postsynaptic receptors may not adjust to the large variation in dopamine levels and thus produce an abnormally decreased dopamine stimulation during the circadian trough of dopamine activity. This trough, as proposed by Earley and colleagues (52), roughly corresponds to the period of RLS symptoms.

Evidence on iron deficiency in RLS is now well documented. Two studies showed that serum ferritin levels inversely correlated with RLS severity $(65,66)$. Researchers in this field have gained further insight using MRI to estimate iron levels in the brain. Two MRI studies $(68,69)$ and a B-mode transcranial ultrasound imaging study (70) showed reduced nigral iron in patients with RLS compared to controls. Furthermore, two cerebral spinal fluid (CSF) studies $(53,74)$ reported that patients with RLS, compared to matched controls, had significant decreases in CSF ferritin. Finally, decreased iron and ferritin have been reported in stained sections of substantia nigra of patients with RLS (71). Therefore, there is evidence, both from peripheral and central measures, supporting a significant iron deficiency in patients with RLS.

Additionally, Zhao et al (75) showed that locomotor activities were increased significantly in mice treated with an iron deficient diet, and also found a change in the expression of the different dopamine receptors. Connor et al (72) showed that RLS may result from a defect in the iron regulatory protein 1 in neuromelanin cells that promote destabilization of transferrin receptor $m$ RNA, leading to cellular iron deficiency. Behavioral tests showed that the locomotor activities were increased significantly in the mice treated with iron deficiency diet and 6-hydroxydopamine (6-OHDA) lesions, which were reversed by the D2/D3 mRNA and protein levels as well as their biding capacity in the spinal cord were decreased significantly by 6-OHDA lesions. Iron deficiency with 6-OHDA lesions produced a synergistic greater decrease of D2 binding (75).

Increasing evidence has suggested RLS may be comorbid with Tourette's syndrome and attentiondeficit/hyperactivity disorder (ADHD) as it has been hypothesized by Cortese et al (76) that iron deficiency contributes to the pathophysiology underlying the spectrum of these 3 disorders. It has been proposed that iron deficiency may lead to ADHD, RLS, and Tourette's syndrome symptoms via its impact on the metabolism of dopamine which has been implicated in the pathophysiology of all of these disorders. In 2005, published clinical reports that $44 \%$ of subjects in with ADHD were also found to have had RLS or RLS symptoms. Lesperance et al (77) reported that RLS was present in $10 \%$ of patients with Tourette's syndrome and $23 \%$ of their parents. Although these studies had their limitations, these potential co-morbidities further suggest iron deficiency contributes to the pathophysiology underlying this spectrum that includes RLS.

Further support comes from Konofal et al (78) where they found data showing a trend for lower serum ferritin in children with ADHD + RLS compared to children with ADHD only. Oner et al (79) also showed that the rate of iron deficiency was significantly higher in ADHD subjects with RLS when compared to ADHD subjects without RLS, thus their results showed that depleted iron stores may actually increase the risk of having RLS in patients with ADHD.

Some of the most supportive evidence of iron deficiency being a potential cause of RLS can be seen in the therapy of RLS related to iron deficiency. Iron supplementation has actually been shown to improve RLS in patients with iron deficiency but not in patients with normal iron levels $(54,67,73,80)$. In a small placebo-controlled trial in RLS secondary to uremia $(n=11)$, RLS symptoms significantly, but transiently, improved with 1000-mg iron dextran (54). In an open trial with 10 patients of whom 4 patients had ferritin levels below $50 \mathrm{mcg} / \mathrm{L}$, a single infusion of $1000-\mathrm{mg}$ iron dextran led to a dramatic improvement of RLS symptoms as assessed on a visual analog scale in 6 patients, whereas 4 patients did not respond to treatment (80). It has been proposed that more frequent smaller doses may be more effective than a single larger dose (81). Oral iron supplementation would not be expected to be all that helpful when there is no iron deficiency or in conditions where iron absorption is impaired (e.g. perhaps during PPI therapy).

An important unanswered question is the consideration of what level of iron deficiency has physiological significance. Although the widely accepted cutoff for serum ferritin is $12 \mathrm{mcg} / \mathrm{L}$, it has been found that 
peripheral iron stores are not fully replenished until a much higher serum ferritin level is present (50-100 $\mathrm{mcg} / \mathrm{L}$ ) (82). Wang and colleagues (83) performed a randomized, placebo-controlled double-blinded study of oral iron therapy in patients with RLS and serum ferritin levels between 15 and $75 \mathrm{mcg} / \mathrm{L}$, using a validated RLS symptom severity scale as an outcome measure. There were 11 subjects taking iron (ferrous sulfate 325 mg twice a day for 3 months) and 7 taking placebo. Both groups were well matched on the International RLS Severity Score and on serum ferritin at baseline. In this study, the iron treatment group had a statistically significant improvement in the RLS symptoms compared to the placebo group, and more importantly, the serum ferritin levels increased by over $60 \%$ in the iron treatment group (83). Earley (84) opined that there is sufficient data from case reports, openlabel trials, and a randomized, double-blinded trial (83) to conclude that patients with RLS should have their serum ferritin levels checked, and even those with low "normal" levels should be treated with oral iron agents to try to raise their ferritin levels to at least $75 \mathrm{mcg} / \mathrm{L}$.

\section{Endogenous Opioids and RLS}

Opioids effectively treat RLS as shown in a doubleblind and long-term studies $(85,6)$. Opioid receptor PET scans show post-synaptic binding of ligand that is inversely proportional to the severity of RLS symptoms in areas serving the medial pain system including the thalamus (87). If naloxone, an opioid antagonist, is given in a double-blind fashion to opioid treated RLS patients, the motor and sensory signs and symptoms return in a qualitative and quantitative fashion (88, 89). Additional receptor blocking studies indicate that opioids have their impact on RLS symptoms by modulating the dopamine system.

In a pilot post-mortem study, Walters et al (90) measured Beta endorphin, Met-enkephalin, and Leuenkephalin levels in thalamus and substantia nigra of RLS patients ( $5 \mathrm{~F}$ - average age 80.2 years) compared to controls (5 F, $1 \mathrm{M}$ - average age 76.3 years). In the thalamus, there were reductions of Beta-endorphin and Met-enkephalin positive cells by $37.5 \%$ ( $P=$ .006 , effect size 2.16$)$ and $26.4 \%(P=.028$, effect size 1.58), respectively, in RLS patients compared to controls. There was no difference in Leu-enkephalin, in the thalamus or changes in Beta endorphin, Met-enkephalin, Leu-enkephalin, or Tyrosine Hydroxylase in the substantia nigra (90). Walters and colleagues (90) concluded that their results suggested that there may be altered central processing of pain in RLS and these data further implicate the endogenous opioid system (likely the $\mathrm{m} \mu$ opioid receptor) in the pathogenesis of RLS.

As above, the most convincing pathological evidence to date is that iron is profoundly decreased in RLS brains as determined by cerebrospinal fluid (CSF), MRI, and autopsy studies $(90,91)$. It is known that iron impacts opioid activity (90). Iron deficient rats have a decreased pain threshold which can be modified by Beta-endorphin administration which has analgesic effects (92). It is therefore possible that decreased iron levels directly lead to thalamic opioid hypofunction $(90,91)$.

\section{PPIs and RLS}

There is no direct evidence linking PPI and RLS. In fact, there is not even any significant indirect evidence of such a link, however, over the past 2 years of patients on PPIs, the authors have been involved with the health care of 29 patients taking with PPIs who also had iron deficiency and 23 of these patients had RLS-like symptoms. One patient on PPI therapy had a serum ferritin of 4 and significant RLSAP. She stopped taking her PPI, and within 5 weeks of PPI cessation, her RLSAP/RLS symptoms resolved completely and her serum ferritin increased to 153. In a study of medication use obtained from 110 RLS patients and 54 control subjects matched for age, race, and gender, significantly more of the RLS patients than controls used PPIs (93).

\section{SUMMARY}

The authors have postulated a relationship between PPIs and iron deficiency as well as the correlation between iron deficiency and RLS and between PPIs and RLS/RLSAP. Thus, the authors suggest that large multicenter studies exploring what happens to iron/ferritin compared to baseline over time with long-term high dose therapy with potent PPIs as well as if a subpopulation exists who develop low serum ferritin values, and also eventually develop RLS-like/ RLSAP-like symptoms. 


\section{References}

1. O'Keeffe ST. Restless legs syndrome. A review. Arch Intern Med 1996; 156:243248.

2. Walters AS. Toward a better definition of the restless legs syndrome. The International Restless Legs Syndrome Study Group. Mov Disord 1995; 10:634-642.

3. Walters AS, LeBrocq C, Dhar A, Hening W, Rosen R, Allen RP, Trenkwalder C; International Restless Legs Syndrome Study Group. Validation of the International Restless Legs Syndrome Study Group rating scale for restless legs syndrome. Sleep Med 2003; 4:121-132.

4. Allen RP, Picchietti D, Hening WA, Trenkwalder C, Walters AS, Montplaisi J; International Restless Legs Syndrome Study Group. Restless legs syndrome: Diagnostic criteria, special considerations and epidemiology. A report from the restless legs syndrome diagnosis and epidemiology workshop at the $\mathrm{Na}$ tional Institutes of Health. Sleep Med 2003; 4:101-119.

5. Hening WA, Allen RP, Washburn M, Lesage S, Earley CJ. Validation of the Hopkins telephone diagnostic interview for restless legs syndrome. Sleep Med 2008; 3:283-289.

6. Hening W, Allen R, Washburn M, Lesage S, Earley C. Mimics of the restless legs syndrome can often satisfy the standard diagnostic critera (abstr.). Sleep 2004; 27:A297.

7. Phillips B, Young T, Finn L, Asher K, Hening WA, Purvis C. Epidemiology of restless legs symptoms in adults. Arch Intern Med 2000; 160:2137-2141.

8. Montplaisir, J, Boucher, S, Poirier, G, Lavigne G, Lapierre O, Lespérance P. Clinical, polysomnographic, and genetic characteristics of restless legs syndrome: A study of 133 patients diagnosed with new standard criteria. Mov Disord 1997; 12:61-65.

9. Oertel WH, Trenkwalder C, Zucconi M, Benes H, Borreguero DG, Bassetti C, Partinen M, Ferini-Strambi L, StiasnyKolster K. State of the art in restless legs syndrome therapy: Practice recommendations for treating restless legs syndrome. Movement Disorders 2007; 22:S466-S475.

10. Trenkwalder C, Hening WA, Montagna P, Oertel WH, Allen RP, Walters AS, Costa J, Stiasny-Kolster K, Sampaio C. Treatment of restless legs syndrome: An evidence-based review and implications for clinical practice. Mov Disord 2008; 23:2267-2302.

11. Winkelmann J, Wetter TC, Collado-Seidel V, Gasser T, Dichgans M, Yassouridis A, Trenkwalder C. Clinical characteristics and frequency of the hereditary restless legs syndrome in a population of 300 patients. Sleep 2000; 23:597602.

12. Hening W, Allen R, Earley C, Kushida C, Picchietti $D$, Silber M. The treatment of restless legs syndrome and periodic limb movement disorder. An American Academy of Sleep Medicine Review. Sleep 1999; 22:970-999.

13. Stiasny-Kolster K, Magerl W, Oertel WH, Möller JC, Treede RD. Static mechanical hyperalgesia without dynamic tactile allodynia in patients with restless legs syndrome. Brain 2004; 127:773-782.

14. Paulus W, Dowling P, Rijsman R, Stias ny-Kolster K, Trenkwalder C, de Weerd A. Pathophysiological concepts of restless legs syndrome. Mov Disord 2007; 22:1451-1456.

15. Polydefkis M, Allen RP, Hauer P, Earley CJ, Griffin JW, McArthur JC. Subclinical sensory neuropathy in late-onset restless legs syndrome. Neurology 2000; 55:1115-1121.

16. Schattschneider J, Bode A, Wasner G, Binder A, Deuschl G, Baron R. Idiopathic restless legs syndrome: Abnormalities in central somatosensory processing. J Neurol 2004; 251: 977-982.

17. Gemignani F, Brindani F, Negrotti $A$, Vitetta F, Alfieri S, Marbini A. Restless legs syndrome and polyneuropathy. Mov Disord 2006; 21: 1254-1257.

18. Gemignani F, Bridani F, Vitetta F, Marbini A. Restless leg syndrome and pain neuropathy - retrospective study. A role for nociceptive deafferentation? Pain Med In Press.

19. Fields $H L$, Rowbotham $M$, Baron $R$. Postherpetic neuralgia: Irritable nociceptors and deafferentation. Neurobiol Dis 1998; 5:209-227.

20. Baumgärtner U, Magerl W, Klein T, Hopf HC, Treede RD. Neurogenic hyperalgesia versus painful hypoalgesia: Two distinct mechanisms of neuropathic pain. Pain 2002; 96:141-151.

21. Allen RP, Earley CJ. Validation of the Johns Hopkins restless legs severity scale. Sleep Med 2001; 2:239-242.

22. Cook JD, Skikne BS, Lynch SR, Reusser ME. Estimates of iron sufficiency in the
US population. Blood 1986; 68:726731.

23. McCance RA, Widdowson EM. The absorption and excretion of iron following oral and intravenous administration. J Phys 1938; 94:148-154.

24. Hallberg L. Bioavailability of dietary iron in man. Annu Rev Nutr 1981; 1:123127.

25. Bezwoda W, Charlton R, Bothwell T, Torrance J, Mayet $F$. The importance of gastric hydrochloric acid in the absorption of nonheme food iron. J Lab Clin Med 1978; 92:108-116.

26. Lind T, Rydberg L, Kylebäck A, Jonsson A, Andersson T, Hasslegren G, Holmberg J, Röhss K. Esomeprazole provides improved acid control vs. omeprazole in patients with symptoms of gastrooesophageal reflux disease. Aliment Pharmacol Ther 2000; 14:861-867.

27. Champagne ET. Low gastric hydrochloric acid secretion and mineral bioavailability. Adv Exp Med Biol 1989; 249:173-184.

28. Archambault AP, Rovelstad RA, Carlson HC. In situ pH of duodenal bulb contents in normal and duodenal ulcer subjects. Gastroenterology 1967; 52:940-947.

29. Schade SG, Cohen RJ, Conrad ME. Effect of hydrochloric acid on iron absorption. N Engl J Med 1968; 279:672674.

30. Miret S, Simpson RJ, McKie AT. Physiology and molecular biology of dietary iron absorption. Annu Rev Nutr 2003; 23:283-301.

31. Zoller H, Koch RO, Theurl T, Obrist P, Pietrangelo A, Montosi G, Haile DJ, Vogel W, Weiss $G$. Expression of the duodenal iron transporters divalent-metal transporter 1 and ferroportin 1 in iron deficiency and iron overload. Gastroenterology 2001; 120:1412-1419.

32. Griffiths WJ, Sly WS, Cox TM. Intestinal iron uptake determined by divalent metal transporter is enhanced in HFEdeficient mice with hemochromatosis. Gastroenterology 2001; 120:14201429.

33. Stuart KA, Anderson GJ, Frazer DM, Powell LW, McCullen M, Fletcher LM, Crawford DH. Duodenal expression of iron transport molecules in untreated haemochromatosis subjects. Gut 2003; 52:953-959.

34. Nemeth E, Tuttle MS, Powelson J, 
Vaughn MB, Donovan A, Ward DM, Ganz T, Kaplan J. Hepcidin regulates cellular iron efflux by binding to ferroportin and inducing its internalization. Science 2004; 306:2090-2093.

35. Bridle KR, Frazer DM, Wilkins SJ, Dixon JL, Purdie DM, Crawford DH, Subramaniam VN, Powell LW, Anderson GJ, Ramm GA. Disrupted hepcidin regulation in HFE-related haemochromatosis and the liver as a regulator of body iron homoeostasis. Lancet 2003; 361:669673.

36. Gehrke SG, Kulaksiz H, Herrmann T, Riedel HD, Bents K, Veltkamp C, Strem mel W. Expression of hepcidin in hereditary hemochromatosis: Evidence for a regulation in response to serum trans ferrin saturation and non-transferrinbound iron. Blood 2003; 102:371-376.

37. Muir A, Hopfer U. Regional specificity of iron uptake by small intestinal brush-boarder membranes from normal and iron deficient mice. Gastrointestinal and Liver Pathology 1985; 11:6376-6379.

38. Koop H, Bachem M G. Serum iron, ferritin, and vitamin $\mathrm{B} 12$ during prolonged omeprazole therapy. J Clin Gastroenterol 1992; 14:288-292.

39. Stewart C, Termanini V, Sutliff VE, Serrano J, Yu F, Gibril F, Kensen R.T. Iron absorption in patients with Zollinger-Ellison Syndrome treated with long-term gastric acid antisecretory therapy. Ailment Pharmacol Ther 1998; 12:83-98.

40. Hutchinson C, Giessler C, Powell J, Bomford A. Proton pump inhibitors suppress absorption of dietary nonhaem iron in hereditary haemochromatosis. Gut 2007; 56:1291-1295.

41. Lynch SR, Skikne BS, Cook JD. Food iron absorption in idiopathic hemochromatosis. Blood 1989; 74:2187-2193.

42. Powell LW, Campbell CB, Wilson E. Intestinal mucosal uptake of iron and iron retention in idiopathic haemochromatosis as evidence for a mucosal abnormality. Gut 1970; 11:727-731.

43. Marx JJM. Mucosal uptake, mucosal transfer and retention of iron, measured by whole-body counting. Scand J Haematol 1979; 23:293-302.

44. Turnbull A, Cleton F, Finch CA. Iron absorption. IV. The absorption of hemoglobin iron. J Clin Invest 1962; 41:18971907.

45. Pietrangelo A. Hereditary hemochromatosis: A new look at an old disease. N Eng J Med 2004; 350:2383-2397.

46. Dooley J, Worwood M. Guidelines on diagnosis and therapy: Genetic haemochromatosis. British Committee for Standards in Haematology 2000. Abingdon, Oxford, Darwin Medical Communications Ltd. www.bcshguidelines.com/.

47. Ekbom KA. Restless legs. Ivar Haeggströms; Stockholm, 1945.

48. Nordlander NB. Restless Legs. BrJ Phys Med 1954; 17:160 -162.

49. Nordlander NB. Therapy in restless legs. Acta Med Scand 1953; 145:453457.

50. Turjanski N, Lees AJ, Brooks DJ. Striatal dopaminergic function in restless legs syndrome: $18 \mathrm{~F}$-dopa and $11 \mathrm{C}$-raclopride PET studies. Neurology 1999; 52:932-937.

51. Akyol A, Kiylioglu N, Kadikoylu G, Bolaman AZ, Ozgel N. Iron deficiency anemia and restless legs syndrome: Is there an electrophysiological abnormality? Clin Neurol Neurosurg 2003; 106:23-27.

52. Earley CJ, Allen RP, Beard JL, Connor JR. Insight into the pathophysiology of restless legs syndrome. J Neurosci Res 2000; 62:623-628.

53. Earley CJ, Connor JR, Beard JL, Alecki EA, Epstein DK, Allen RP. Abnormalities in CSF concentrations of ferritin and transferring in restless legs syndrome. Neurology 2000; 54:1698-1700.

54. Sloand JA, Shelly MA, Feigin A, Bernstein P, Monk RD. A double-blind, placebo-controlled trial of intravenous iron dextran therapy in patients with ESRD and restless legs syndrome. Am J Kidney Dis 2004; 43:663- 670.

55. Manconi M, Govoni V, De Vito A, Economou NT, Cesnik E, Mollica G, Granieri E. Pregnancy as a risk factor for restless legs syndrome. Sleep Med 2004; 5:305-308.

56. O’Keeffe ST, Noel J, Lavan JN. Restless legs syndrome in the elderly. Postgrad Med J 1993; 69:701-703.

57. Ekbom KA. Restless legs syndrome after partial gastrectomy. Acute Neurol Scand 1966; 42:79-89.

58. Happe S, Tings T, Schettler V, Canelo M, Paulus W, Trenkwalder C. Low-density lipoprotein apheresis and restless legs syndrome. Sleep 2003; 26:A335A336.

59. Tings T, Schettler V, Canelo M, Paulus W, Trenkwalder C. Impact of regular LDL apheresis on the development of restless legs syndrome. Mov Disord 2004; 19:1072-1075. 6o. Hogl B, Kiechl S, Willeit J, Saletu M, Frauscher B, Seppi K, Müller J, Rungger G, Gasperi A, Wenning G, Poewe W. Restless legs syndrome: A community-based study of prevalence, severity, and risk factors. Neurology 2005; 64:1920-1924.

61. Berger K, von Eckardstein A, Trenkwalder C, Rothdach A, Junker R, Weiland SK. Iron metabolism and the risk of restless legs syndrome in an elderly general population - the MEMO-Study. J Neurol 2002; 249:1195-1199.

62. Alvarez-Ossorio L, Kirchner H, Kluter $\mathrm{H}$, Schlenke P. Low ferritin levels indicate the need for iron supplementation: Strategy to minimize iron-depletion in regular blood donors. Transfus Med 2000; 10:107-112.

63. Guyatt GH, Patterson C, Ali M, Singer J, Levine M, Turpie I, Meyer R. Diagnosis of iron-deficiency anemia in the elderly. Am J Med 1990; 88:205-209.

64. Silber MH, Ehrenberg BL, Allen RP, Buchfuhrer MJ, Earley CJ, Hening WA, Rye DB; Medical Advisory Board of the Restless Legs Syndrome Foundation. An algorithm for the management of restless legs syndrome. Mayo Clin Proc 2004; 79:916-922.

65. O'Keeffe ST, Gavin K, Lavan JN. Iron status and restless legs syndrome in the elderly. Age Ageing 1994; 23:200-203.

66. Sun ER, Chen CA, Ho G, Earley CJ, Allen RP. Iron and the restless legs syndrome. Sleep 1998; 21:371-377.

67. Wang Y, Mysliviec V, Fischer C, Dehaan P, Owshalipur D, Mysliviec A. Efficacy of iron in patients with restless legs syndrome and a low-normal ferritin: A randomized, double-blind, placebo controlled study. In: Association of Professional Sleep Societies. Sleep. Salt Lake City, Utah, USA, 2006. p A273.

68. Earley CJ, Barker PB, Horska A, Allen RP. MRI-determined regional brain iron concentrations in early- and late-onset restless legs syndrome. Sleep Med 2006; 7:459-461.

69. Allen RP, Barker PB, Wehrl F, Song HK, Earley CJ. MRI measurement of brain iron in patients with restless legs syndrome. Neurology 2001; 56:263-265.

70. Schmidauer C, Sojer M, Seppi K, Stockner H, Högl B, Bidermann B, Brandauer E, Peralta CM, Wenning GK, Poewe W. Transcranial ultrasound shows nigral hypoechogenicity in restless legs syndrome. Ann Neurol 2005; 58:630-634.

71. Connor JR, Boyer PJ, Menzies SL, Dellinger B, Allen RP, Earley CJ. Neuro- 
pathological examination suggests impaired brain iron acquisition in restless legs syndrome. Neurology 2003; 61:304-309.

72. Connor JR, Wang XS, Patton SM, Menzies SL, Tronocoso JC, Earley CJ, Allen RP. Decreased transferrin receptor expression by neuromelanin cells in restless legs syndrome. Neurology 2004; 62:1563-1567.

73. Earley CJ, Heckler D, Allen RP. IV Iron treatment for the restless legs syndrome (RLS). Sleep 2001; 24:A359.

74. Mizuno S, Mihara T, Miyaoka T, Inagaki T, Horiguchi J. CSF iron, ferritin and transferrin levels in restless legs syndrome. J Sleep Res 2005;14:43-47.

75. Zhao H, Zhu W, Pan T, Xie W, Zhang A, Ondo WG, Le W. Spinal cord dopamine receptor expression and function in mice with 6-OHDA lesion of the A11 nucleus and dietary iron deprivation. J Neurosco Res 2007; 85:1065-1076.

76. Cortese S, Lecendreux M, Bernardina BD, Mouren MC, Sbarbati A, Konofal E. Attention-deficit/hyperactivity disorder, Tourette's syndrome, and restless legs syndrome: The iron hypothesis. Med Hypotheses 2008; 70:1128-1132.

77. Lespérance P, Djerroud N, Diaz Anzaldua A, Rouleau GA, Chouinard S, Richer F, Montréal Tourette Study Group. Restless legs in Tourette syndrome. Mov Disord 2004; 19:1084-1087.

78. Konofal E, Cortese S, Marchand M, Mouren MC, Arnulf I, Lecendreux M. Impact of restless legs syndrome and iron deficiency on attention-deficit/hyperactivity disorder in children. Sleep Med 2007; 8:711-715.
79. Oner P, Dirik EB, Taner Y, Caykoylu A, Anlar O. Association between low serum ferritin and restless legs syndrome in patients with attention deficit hyperactivity disorder. Tohoku J Exp Med 2007; 213:269-276.

80. Earley CJ, Heckler D, Allen RP. The treatment of restless legs syndrome with intravenous iron dextran. Sleep Med 2004; 5:231-235.

81. Earley C, Heckler D, Allen RD. Repeated IV doses of iron provides effective supplemental treatment of restless legs syndrome. Sleep Med 2005; 6:301305.

82. Sharma VR, Brannon MA, Carloss EA. Effect of omeprazole on oral iron replacement in patients with iron deficiency anemia. South Med J 2004; 97; 887-889.

83. Wang J, O’Reilly B, Venkataraman R, Mysliwiec V, Mysliwiec A. Efficacy of oral iron in patients with restless legs syndrome and a low-normal ferritin: A randomized, double-blind, placebocontrolled study. Sleep Med 2009 In Press.

84. Earley CJ. The importance of oral iron therapy in restless legs syndrome. Sleep Med 2009, In Press.

85. Walters AS, Wagner ML, Hening WA, Grasing K, Mills R, Chokroverty S Kavey N. Successful treatment of the idiopathic restless legs syndrome in a randomized double blind trial of oxycodone versus placebo. Sleep 1993; 16:327332.

86. Walters AS, Winkelmann J, Trenkwalder C, Fry JM, Kataria V,Wagner M, Sharma R, Hening W, Li L. Longterm follow- up on restless legs syndrome patients treated with opioids. Mov Disord 2001; 16:1105-1109.

87. Von Spiczak S, Whone AL, Hammers A, Asselin MC, Turkheimer F, Tings T, Happe S, Paulus W, Trenkwalder C, Brooks DJ. The role of opioids in restless legs syndrome: $\mathrm{An}(11 \mathrm{C})$ diprenorphine PET study. Brain 2005; 128:906917.

88. Hening W, Walters A, Kavey N, GidroFrank S, Cote L, Fahn S. Dyskinesia while awake and periodic movements of sleep in restless legs syndrome: treatment with opioids. Neurology 1986; 36:1363-1366.

89. Walters A, Hening W, Cote L, Fahn S. Dominantly inherited restless legs with myoclonus and periodic movements of sleep: A syndrome related to the endogenous opiates? Adv Neurol 1986; 43:309-319.

90. Walters AS, Ondo WG, Zhu W, Le W. Does the endogenous opiate system play a role in the restless legs syndrome?: A pilot post-mortem study. J Neurolog Sci 2009; 279:62-65.

91. Connor JR. Pathophysiology of restless legs syndrome: Evidence for iron involvement. Curr Neurol Neurosci Rep 2008; 8:162-166.

92. Yehuda S, Youdim MB. Brain iron: A lesson from animal models. Am J Clin Nutrn 1989; 50:618-625.

93. Pearson VE, Gamaldo CE, Allen RP, Lesage $S$, Hening WA, Earley CJ. Medication use in patients with restless legs syndrome compared with a control population. Eur J Neuro 2008; 15:1621. 
